\title{
Cardiovascular safety assessment of pramlintide in type 2 diabetes: results from a pooled analysis of five clinical trials
}

\author{
Kathrin Herrmann", Ming Zhou², Andrew Wang ${ }^{2}$ and Tjerk W. A. de Bruin ${ }^{3 *}$
}

\begin{abstract}
Background: This report evaluated the cardiovascular safety of the amylin analog pramlintide —an existing diabetes injectable treatment-by comparing relevant cardiovascular adverse events (AEs) reported in previous phase 3 and 4 clinical trials among patients receiving pramlintide and those receiving control treatments.

Methods: Cardiovascular safety of pramlintide was assessed using accepted regulatory medical definitions of AEs reported in five randomized, controlled phase 3 and 4 trials of 16-52 weeks' duration in adults with type 2 diabetes. The original trials compared pramlintide (90-120 mcg twice daily or 30-150 mcg three times daily) with placebo (four studies) or a mealtime rapid-acting insulin analog (one study). Background therapies included insulin alone or in combination with oral glucose-lowering agents. AE data obtained from clinical study reports were combined into one database and analyzed for the intention-to-treat population of 2016 patients (pramlintide, $n=1434$; pooled comparator, $n=582$ ). The primary analysis compared reported major adverse cardiovascular events (MACE) between pramlintide and control.
\end{abstract}

Results: The incidence of reported MACE was similar between pramlintide (4.7\%) and pooled comparators (4.5\%). Secondary analyses included MACE relative risk and hazard ratio point estimates, which ranged from 0.86 to 0.93 for pramlintide relative to comparator treatment; the upper limit of the two-sided $95 \%$ confidence interval did not exceed the threshold of 1.8 .

Conclusions: Both the point estimate of the reported MACE frequency and estimated risk ratios showed that mealtime pramlintide as an adjunct to insulin conferred no increased risk of cardiovascular AEs in patients with type 2 diabetes using insulin.

Keywords: Amylin, Cardiovascular safety, Insulin, Major adverse cardiovascular events, Pramlintide, Type 2 diabetes

\section{Background}

Diabetes mellitus is a complex disease that is progressive in nature and involves a disrupted interplay of glucoregulatory hormones. In normal physiology, insulin and amylin are co-secreted by pancreatic $\beta$ cells in response to meals. Both insulin and amylin responses to food intake are altered in patients with type 2 diabetes and absent in patients with type 1 diabetes, because of autoimmune $\beta$-cell destruction $[1,2]$.

\footnotetext{
* Correspondence: tjerk.debruin@astrazeneca.com

${ }^{3}$ AstraZeneca CVMD GMD, One Medimmune Way, Gaithersburg, MD 20878, USA

Full list of author information is available at the end of the article
}

Pramlintide is a soluble analog of amylin, a neuroregulatory hormone that slows the rate of gastric emptying and decreases food intake in the long term by acting on the efferent vagal nerve [3, 4]. Additionally, pramlintide attenuates immediate postprandial glucagon secretion, which in turn can reduce hepatic glucose production $[4,5]$. Combined, the mechanisms of action of pramlintide contribute to reduced glycemia following ingestion of exogenous glucose $[2,4,6-8]$.

Pramlintide at doses of 30 and $60 \mathrm{mcg}$ in patients with type 1 diabetes and at a dose of $120 \mathrm{mcg}$ in patients with type 2 diabetes has been shown to result in plasma pramlintide concentrations that approximate physiological postprandial plasma amylin concentrations in 
healthy subjects [8]. Placebo-controlled clinical trials of pramlintide in type 1 diabetes [9-11] and type 2 diabetes [12-14] have shown that mealtime pramlintide injections as an adjunct to mealtime insulin significantly reduce glycated hemoglobin (HbA1c) levels (by 0.3-0.7\% and $0.3-1.0 \%$, respectively) and body weight (by $0.4-$ $1.4 \mathrm{~kg}$ and $0.5-1.8 \mathrm{~kg}$ in type 1 and type 2 diabetes, respectively). The most commonly reported adverse events (AEs) were nausea, vomiting, anorexia or reduced appetite, and severe hypoglycemia in studies in patients with type 1 diabetes (when the insulin dose was not simultaneously reduced), and nausea and mild to moderate hypoglycemia in studies in patients with type 2 diabetes $[9-12,15,16]$.

In this report, an evaluation of cardiovascular safety of pramlintide was conducted using accepted regulatory medical definitions of AEs in five previous randomized, controlled phase 3 and 4 trials of 16- to 52-weeks' duration in adults with type 2 diabetes.

\section{Methods}

\section{Study selection}

This assessment analyzed data from an integrated database of all randomized controlled trials of pramlintide with a duration of 16 to 52 weeks conducted in patients with type 2 diabetes (Table 1). Cardiovascular safety of pramlintide-an existing injectable mealtime treatment for diabetes in adjunct with insulin-was assessed using accepted regulatory medical definitions of AEs reported in five randomized, controlled phase 3 and 4 trials of 16- to 52-weeks' duration in adults with type 2 diabetes. The original trials compared pramlintide $(90-120 \mathrm{mcg}$ twice daily or $30,60,75,120$, or $150 \mathrm{mcg}$ three times daily; Table 1) with placebo (four studies) or a mealtime rapidacting insulin analog (one study) [12-16]. Background therapies included insulin alone or in combination with oral glucose-lowering agents. AE data were obtained from clinical study reports, which were combined into one database. The studies used in the present report are summarized in Table 1, and the demographics and patient characteristics are shown in Table 2. Cardiovascular events were not prospectively adjudicated. Clinical study reports were the source of the reports of cardiovascular events. Safety events were combined into one database for the intention-to-treat population of 2016 patients (pramlintide, $n=1434$; pooled comparators, $n=582$ ). The primary analysis compared major adverse cardiovascular events (MACE) for pramlintide and control treatments, an approach that has been applied to other existing diabetes treatments [17-19]. The protocol of each trial was approved by the respective institutional review board, all participants provided written informed consent prior to study entry, and the studies were conducted in accordance with the principles defined by the Declaration of Helsinki.

\section{Cardiovascular events}

Cardiovascular safety of pramlintide was assessed using standardized medical definitions (queries) of AEs listed in the standardized Medical Dictionary for Regulatory

Table 1 Phase 3 and 4 clinical trials with mealtime pramlintide as adjunct to insulin in patients with type 2 diabetes

\begin{tabular}{|c|c|c|c|c|c|}
\hline Reference & Patient population $\left(\mathrm{N}^{\mathrm{a}}\right)$ & $\begin{array}{l}\text { Length } \\
\text { (weeks) }\end{array}$ & Comparator & Study treatments & Background therapy \\
\hline $\begin{array}{l}\text { Ratner et al., } \\
2002 \text { [13] }\end{array}$ & $\begin{array}{l}\text { Type } 2 \text { diabetes }^{\mathrm{b}} \text { requiring insulin }^{\mathrm{c}} \text {; mean } \\
\text { age } 55.5 \text { to } 57.5 \text { y between groups; baseline } \\
\text { HbA1c } 9.0 \% \text { to } 9.3 \% \text { between groups }{ }^{\mathrm{d}} \text { (538) }\end{array}$ & 52 & Placebo & $\begin{array}{l}\text { Pramlintide }(30,75,150 \\
\text { mcg TID) or placebo }\end{array}$ & $\begin{array}{l}\text { Insulin with or without } \\
\text { SFU, metformin }\end{array}$ \\
\hline $\begin{array}{l}\text { Hollander et al., } \\
2003 \text { [12] }\end{array}$ & $\begin{array}{l}\text { Type } 2 \text { diabetes }^{\mathrm{b}} \text { requiring insulin }^{\mathrm{e}} \text {; mean } \\
\text { age } 56.4 \text { to } 57.0 \text { y between groups; baseline } \\
\text { HbA1c } 9.0 \% \text { to } 9.3 \% \text { between groups }{ }^{\mathrm{d}}(656)\end{array}$ & 52 & Placebo & $\begin{array}{l}\text { Pramlintide (60 mcg TID, } \\
90 \text { mcg BID, } 120 \text { mcg BID) } \\
\text { or placebo }\end{array}$ & $\begin{array}{l}\text { Insulin with or without } \\
\text { SFU, metformin }\end{array}$ \\
\hline $\begin{array}{l}\text { AstraZeneca } \\
\text { (data on file) [14] }\end{array}$ & $\begin{array}{l}\text { Type } 2 \text { diabetes }{ }^{\mathrm{b}} \text { requiring insulin } \text {; mean } \\
\text { age } 57.8 \text { y; HbA1c } 9.3 \% \text { to } 9.5 \% \text { between } \\
\text { groups }^{\mathrm{d}} \text { (499) }\end{array}$ & 26 & Placebo & $\begin{array}{l}\text { Pramlintide (90 mcg BID, } \\
120 \text { mcg BID, } 90 \text { mcg TID) } \\
\text { or placebo }\end{array}$ & $\begin{array}{l}\text { Insulin with or without } \\
\text { SFU, metformin }\end{array}$ \\
\hline $\begin{array}{l}\text { Riddle et al., } \\
2007 \text { [15] }\end{array}$ & $\begin{array}{l}\text { Type } 2 \text { diabetes not controlled by insulin } \\
\text { glargine } \mathrm{f}_{\text {; }} \text { mean age } 55 \mathrm{y} \text {; baseline HbA1c } \\
8.5 \%^{\mathrm{g}}(211)\end{array}$ & 16 & Placebo & $\begin{array}{l}\text { Pramlintide (60 or } 120 \text { mcg } \\
\text { BID/TID) versus placebo }\end{array}$ & $\begin{array}{l}\text { Insulin glargine with or } \\
\text { without metformin, SFU, } \\
\text { TZD }\end{array}$ \\
\hline $\begin{array}{l}\text { Riddle et al., } \\
2009 \text { [16] } \\
\text { (phase } 1 \text { only) }\end{array}$ & $\begin{array}{l}\text { Type } 2 \text { diabetes; mean age } 55 \text { y and } 54 \text { y; } \\
\text { baseline } \mathrm{HbA} 1 \mathrm{c} 8.2 \% \text { and } 8.3 \% \text {; insulin-naïve } \\
\text { or used }<50 \mathrm{U} / \mathrm{d} \text { of basal insulin for } \\
<6 \text { months }^{9}(112)\end{array}$ & 24 & $\begin{array}{l}\text { Rapid- } \\
\text { acting } \\
\text { insulin }\end{array}$ & $\begin{array}{l}\text { Pramlintide (60 or } 120 \text { mcg } \\
\text { BID/TID) versus rapid-acting } \\
\text { insulin }\end{array}$ & $\begin{array}{l}\text { Insulin glargine or detemir } \\
\text { with or without metformin, } \\
\text { SFU, TZD }\end{array}$ \\
\hline
\end{tabular}

BID twice daily, SFU sulfonylurea, TID three times daily, TZD thiazolidinedione

${ }^{\text {a } I n t e n t-t o-t r e a t ~ p o p u l a t i o n ~}$

${ }^{\mathrm{b}}$ Free of symptoms of severe hypoglycemia or hyperglycemia for the prior 2 weeks

${ }^{c}$ On a stable insulin dose $( \pm 10 \%)$ during the prior week

${ }^{\mathrm{d} E x c l u d e d}$ patients with heart disease, blood pressure $>150 / 95 \mathrm{~mm} \mathrm{Hg}$ at screening, or hypertension poorly controlled by treatment

eOn a stable total daily insulin dose $( \pm 10 \%)$ during the prior 2 months

fOn a stable insulin dose $( \pm 10 \%)$ during the prior 1 month

${ }^{g}$ Excluded patients who had experienced recurrent severe hypoglycemia requiring assistance during the past 6 months or who had a history of hypoglycemia unawareness 
Table 2 Demographics and baseline characteristics

\begin{tabular}{lll}
\hline Variable & $\begin{array}{l}\text { Pramlintide } \\
(n=1434)\end{array}$ & $\begin{array}{l}\text { Pooled comparator } \\
(n=582)\end{array}$ \\
\hline Sex & $738(51.5)$ & $315(54.1)$ \\
$\quad$ Male & $696(48.5)$ & $267(45.9)$ \\
$\quad$ Female & $57.2 \pm 10.1$ & $55.7 \pm 10.2$ \\
Age (years) & & \\
Race & $1184(82.6)$ & $467(80.2)$ \\
$\quad$ White & $136(9.5)$ & $57(9.8)$ \\
Black & $7(0.5)$ & $3(0.5)$ \\
$\quad$ Asian & $93(6.5)$ & $47(8.1)$ \\
Hispanic & $14(1.0)$ & $8(1.4)$ \\
Other & $93.6 \pm 19.9$ & $94.4 \pm 19.6$ \\
Body weight $(\mathrm{kg})$ & $32.4 \pm 6.2$ & $32.6 \pm 6.4$ \\
Body mass index $\left(\mathrm{kg} / \mathrm{m}^{2}\right)$ & $9.1 \pm 1.2$ & $9.0 \pm 1.3$ \\
HbA1c (\%) & $12.6 \pm 7.3$ & $12.0 \pm 7.0$ \\
Duration of diabetes (years) &
\end{tabular}

Data are shown as $\mathrm{n}(\%)$ or mean \pm standard deviation

HbA1c glycated hemoglobin

Activities (MedDRA) version 12.0, which had been reported by investigators and listed in clinical study reports submitted previously to regulatory authorities or a clinical database. The primary analysis compared the frequency of investigator-reported MACE in the pramlintide and control treatment groups. As widely accepted, MACE included cardiovascular mortality, myocardial infarction, stroke, hospitalization for acute coronary syndrome, and urgent revascularization procedures [20].

There is a theoretical consideration of type I errors (false negatives) if the criteria that constitute the composite end point are too broad, and a consideration of type II errors (false positives) if criteria are too narrow; thus, secondary analyses were performed to confirm the findings of the primary analysis. The secondary analyses included three supplemental, widely accepted definitions of MACE. First, the narrower "subset MACE" category comprised all terms for cardiovascular mortality, myocardial infarction, and stroke. Second, the standardized MedDRA terms for MACE ("SMQ MACE") category encompassed all MedDRA query terms for myocardial infarction, central nervous system hemorrhages, and cerebrovascular accidents [21]; the analysis was done as described in an identical exenatide analysis [22]. Third, a broader set of cardiovascular events ("broad CV") was analyzed, which comprised all query terms for cardiovascular mortality, myocardial infarction, stroke, hospitalization for acute coronary syndrome, urgent revascularization procedures, arrhythmia, heart failure, or mechanical-related events (i.e. all SMQ MACE plus all preferred terms under arrhythmia, heart failure, and mechanical-related events).

\section{Statistical analysis}

Pooled investigator-reported $\mathrm{AE}$ data from the pramlintide treatment group were compared with pooled data on investigator-reported AEs from the placebo and rapid-acting insulin treatment groups. Relative risks (RRs) and hazard ratios (HRs) of cardiovascular events with pramlintide versus control were calculated. The $R R$ corresponding to incidence rate was based on the Mantel-Haenszel method stratified by study, and the HR used the Cox proportional hazard model and the Andersen-Gill model. The threshold for HR and RR point estimates was 1.3 , as widely used [20]. The upper limit of the two-sided $95 \%$ confidence interval (CI) for the estimated risk ratio was defined as 1.8 , as widely used [20]. Kaplan-Meier survival curves weighted according to the number of patients in each study were generated to show the time to first event and proportion of patients risk-free over time. $P$-values using the log-rank test were provided for Kaplan-Meier survival curves. The event rate per 1000 patient-years was calculated based on the Exact method, and the corresponding RR was calculated using the log-normal approximation.

\section{Results}

The number and incidence of investigator-reported cardiovascular events in the pramlintide and pooled comparator treatment groups are listed in Table 3. The incidence of MACE in the pooled data was $4.6 \%$, with no difference observed between the pramlintide (4.7\%) and comparator $(4.5 \%)$ groups. The incidence of fatal events was $0.21 \%(n=3 / 1434)$ in the pramlintide group and $0.69 \%(n=4 / 582)$ in the pooled comparator group.

More detailed analyses were conducted on each of the cardiovascular event categories listed in Table 3. There was no difference between the pramlintide and pooled comparator groups in the incidence of cardiovascular events by any of the measures (Fig. 1). Figure 1 depicts the RR and HR point estimates (and $95 \% \mathrm{CI}$ ) of cardiovascular events according to each category in the pramlintide versus comparator treatment groups. The risk ratios ranged from 0.86 to 0.93 for MACE for pramlintide treatment versus comparator; combined with the $95 \%$ CI shown, the data showed that pramlintide had a similar risk of cardiovascular events as the comparator treatment (Fig. 1). The upper limit of the two-sided $95 \%$ $\mathrm{CI}$ for the estimated risk ratio of primary MACE did not exceed the threshold of 1.8 (0.55-1.34 by MantelHaenszel analysis). For each category of cardiovascular events listed (Table 3; Fig. 1), the upper limit of the twosided $95 \%$ CI was between 1.3 and 1.8 and did not exceed the threshold of 1.8 (Fig. 1). Estimates of RR and HR were consistent for each secondary end point, regardless of the analysis method used. 
Table 3 Comparative incidence of investigator-reported CV events in five pooled clinical trials with pramlintide as adjunct to insulin

\begin{tabular}{|c|c|c|c|}
\hline Event definition, n (\%) & Pramlintide $(n=1434)$ & Pooled comparator $(n=582)$ & Risk ratio $(95 \% \mathrm{Cl})$ \\
\hline \multicolumn{4}{|l|}{ Primary MACE ${ }^{a}$} \\
\hline Incidence, n (\%) & $67(4.7)$ & $26(4.5)$ & \\
\hline Event rate per 1000 patient-years & 95.12 & 91.98 & $1.034(0.694-1.540)$ \\
\hline \multicolumn{4}{|l|}{ Subset MACE ${ }^{\mathrm{b}}$} \\
\hline Incidence, n (\%) & $32(2.2)$ & $12(2.1)$ & \\
\hline Event rate per 1000 patient-years & 37.63 & 36.23 & $1.039(0.551-1.958)$ \\
\hline \multicolumn{4}{|l|}{ SMQ MACE } \\
\hline Incidence, n (\%) & $49(3.4)$ & $15(2.6)$ & \\
\hline Event rate per 1000 patient-years & 60.63 & 50.17 & $1.208(0.712-2.051)$ \\
\hline \multicolumn{4}{|l|}{ Broad CV } \\
\hline Incidence, n (\%) & $127(8.9)$ & $43(7.4)$ & \\
\hline Event rate per 1000 patient-years & 190.24 & 189.53 & $1.004(0.760-1.326)$ \\
\hline
\end{tabular}

Overall incidence in the pooled population was $4.6 \%$ for primary MACE, $2.2 \%$ for subset MACE, $3.2 \%$ for SMQ MACE, and $8.4 \%$ for broad CV

$\mathrm{Cl}$ confidence interval, CV cardiovascular, MACE major adverse cardiovascular events, SMQ MACE standardized Medical Dictionary for Regulatory Activities query for MACE

a Primary MACE included CV mortality, myocardial infarction, stroke, hospitalization for acute coronary syndrome, and urgent revascularization procedures

bSubset MACE included CV mortality, myocardial infarction, and stroke only

'SMQ MACE included myocardial infarction, central nervous system hemorrhages, and cerebrovascular accidents

${ }^{\mathrm{d}}$ Broad CV included CV mortality, myocardial infarction, stroke, hospitalization for acute coronary syndrome, urgent revascularization procedures, arrhythmia, heart failure, or mechanical-related events

\section{Event rates}

Figure 2 depicts the proportion of patients without an event over time, meaning that a treatment that has fewer cardiovascular events would show a larger proportion of event-free patients. The analyses for Fig. 2 used cardiovascular event rates that were weighted by the number of patients in each study. The data showed no excess risk of cardiovascular events in any analysis category with pramlintide versus comparator treatments.

\section{Discussion}

The results indicate that no excess cardiovascular risk was associated with mealtime pramlintide treatment in patients with type 2 diabetes who had inadequate glycemic control. The primary analysis of MACE showed that both the point estimate and range of the $95 \% \mathrm{CI}$ of the estimated risk ratio were consistent with the absence of an increased risk of cardiovascular events. Some point estimates showed possibly less risk of a cardiovascular event in the pramlintide treatment group-when events were in the primary analysis category, MACE. The weighted Kaplan-Meier analysis of primary MACE (Fig. 2) was also consistent with the absence of an increased risk of cardiovascular events. The incidence of fatal cardiovascular events was lower in the pramlintide treatment group compared to the comparator treatment

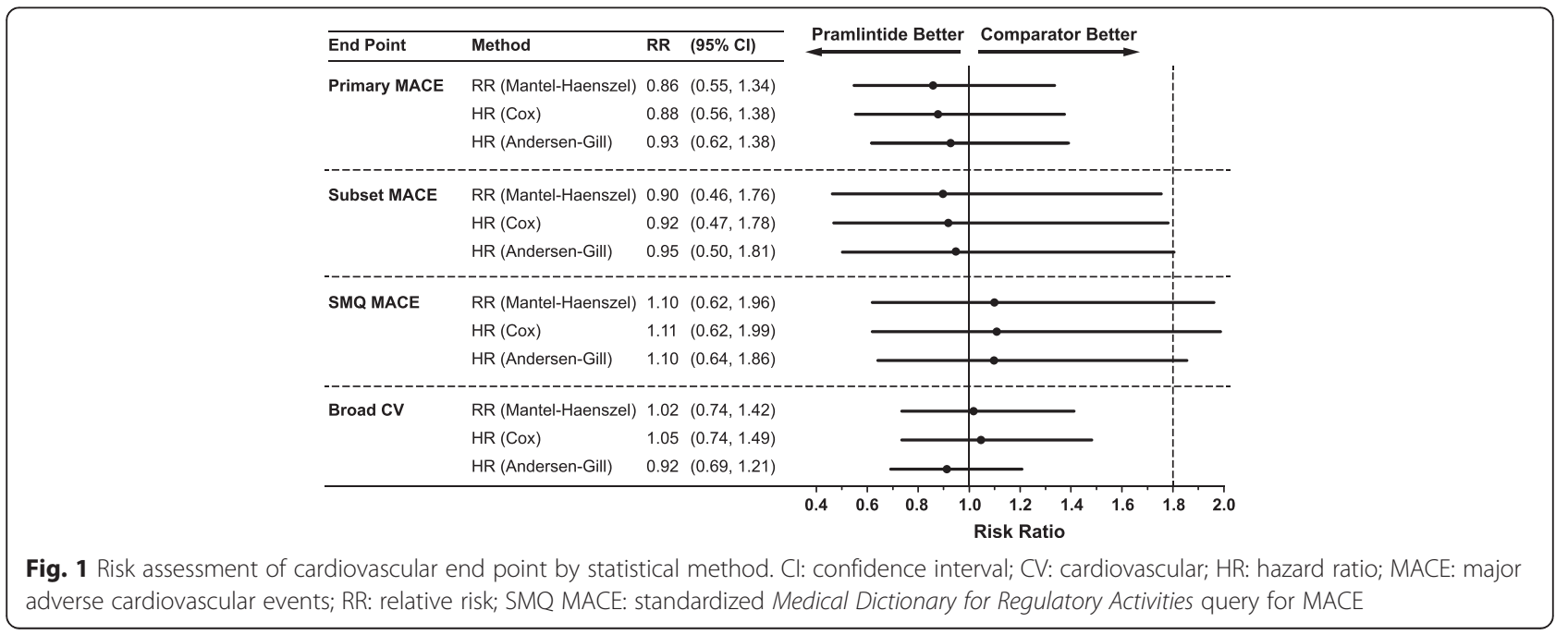


Primary MACE
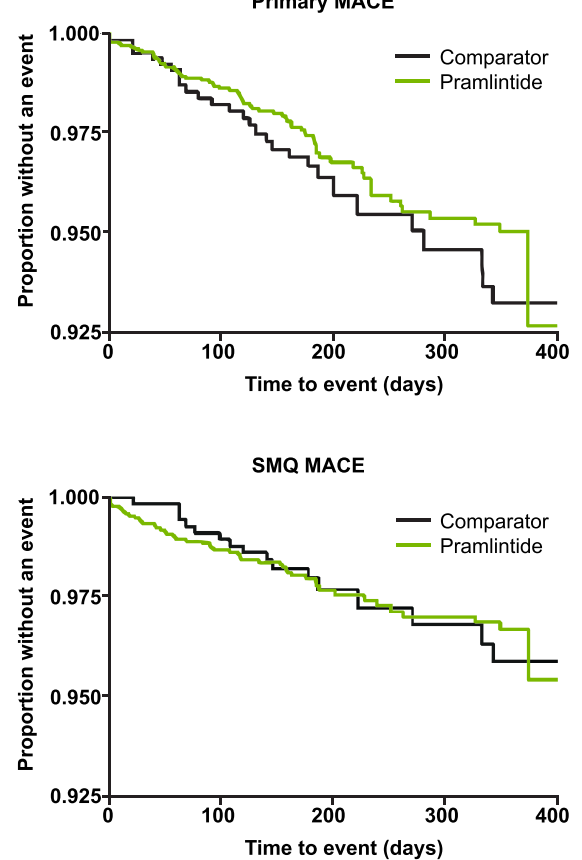

Subset MACE

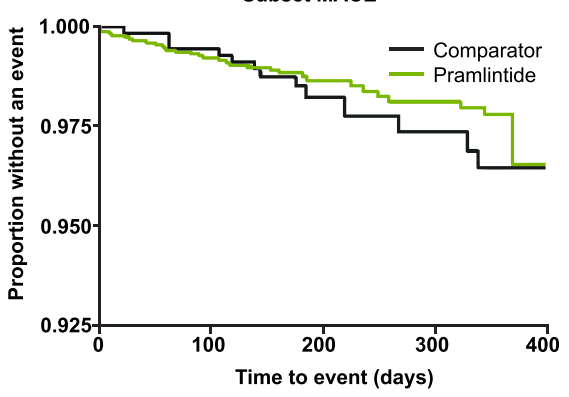

Broad CV

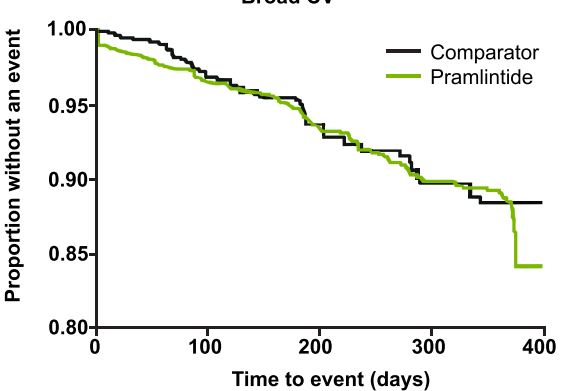

Fig. 2 Weighted Kaplan-Meier plots for time to first event for cardiovascular adverse events. $P$-values using the log-rank test were $P<0.0001$ for primary MACE, $P<0.0001$ for subset MACE, $P=0.3993$ for SMQ MACE, and $P=0.3733$ for broad CV. CV: cardiovasCular; MACE: major adverse cardiovascular events; SMQ MACE: standardized Medical Dictionary for Regulatory Activities query for MACE

group. The secondary analyses were supportive of the primary analysis because no differences between treatment groups in the risk of cardiovascular events were found. The consistency between the various statistical approaches applied to this data set of investigatorreported cardiovascular AEs was reassuring.

The patients enrolled in the first three pramlintide studies reported here were diagnosed with type 2 diabetes with a mean duration of $\geq 12$ years, had mean baseline HbA1c levels $\geq 9.0 \%$ while using insulin, and were overweight (mean weight, $94 \mathrm{~kg}$; mean body mass index, $32-33 \mathrm{~kg} / \mathrm{m}^{2}$ ), corresponding to an increased risk of cardiovascular events, which may be as high as 2-3 times that of the general population [23]. Three of the five pramlintide studies were conducted under the principle of "insulin-equipoise" (i.e. at the time, the instructions for patients were not to adjust the dose of insulin when initiating pramlintide; currently, the US label for pramlintide mandates a reduction by $50 \%$ of mealtime insulin at initiation and subsequent slow up-titration of insulin based on blood glucose levels) [24]. The MACE frequency observed in the pramlintide studies ( $4 \%$ in 1 year) was similar to the ORIGIN cardiovascular outcome study with insulin glargine (MACE frequency approximately $3 \%$ per year) [25], and comparable as well to the MACE frequency in the placebo treatment group in recent cardiovascular outcome studies (between 3 and $4 \%$ per year) [25-28]. In summary, the pooled pramlintide studies were found to have a frequency of cardiovascular events similar to that in cardiovascular outcome studies, supporting the robustness of the findings.

The present retrospective analysis has limitations of a relatively small sample size of approximately 2000 patients, who were generally of middle age, and relatively short observation periods of 16 to 52 weeks. Several existing diabetes treatments presented systematic retrospective analyses to estimate their cardiovascular safety signals, recognizing that cardiovascular events are often not adjudicated [17-19, 22, 29]. These analyses found that glucose-lowering therapies including dipeptidyl peptidase-4 inhibitors and glucagon-like peptide-1 receptor agonists were also not associated with increased cardiovascular risk, while reporting low MACE rates $[17-19,22,29]$. The several-fold lower MACE rates observed in systematic reviews of early clinical development studies were not replicated in formal cardiovascular outcome studies, likely because of differences in inherent baseline cardiovascular risk in study populations [26-28]; however, the initial finding of no excess cardiovascular risk [17-19, 22, 29] was confirmed. Therefore, a potential limitation of retrospective analyses is that too few cardiovascular events might have occurred, because the populations enrolled in pivotal clinical trials is generally healthier with fewer CV risk factors; however, the pooled pramlintide studies analyzed here showed a sufficiently high frequency 
of cardiovascular events ( $4 \%$ over 52 weeks) for these analyses.

It has been recognized that the risk of hypoglycemia is one of the most significant factors that limit optimization of insulin therapy [30, 31]. In general, addition of insulin to the treatment regimen, longer duration of insulin use, and intensive treatment increase the risk of hypoglycemia $[25,30]$. It is of interest that the incidence of severe hypoglycemia was similar between pramlintide and control treatment groups in the studies included in the present analysis [12-16], although the risk of severe hypoglycemia was generally higher during the first weeks following initiation of pramlintide therapy $[12,13]$. The relationship between hypoglycemia and increased cardiovascular risk is not clear at present [30, 32, 33]. Several smaller studies showed associations between low blood glucose and cardiac ischemia [34] and angina (a case study) [35]. More recently, a connection between higher hypoglycemia rates and higher mortality rates in the ACCORD trial was made [36]. However, subsequent post hoc analyses showed that the excess mortality in the intensive treatment group was not directly explained by a higher rate of severe hypoglycemia [37]. Analyses of the ADVANCE trial showed an association between severe hypoglycemia and increased risk of macrovascular events, microvascular events, and cardiovascular death, indicating that hypoglycemia is likely "a marker of vulnerability to a wide range of adverse clinical outcomes" [38]. However, the incidence of severe hypoglycemia was similar for the pramlintide and insulin groups in the studies included in the present analysis.

One recent overview of prospective cardiovascular outcome trials in type 2 diabetes describes evidence that, in patients with type 2 diabetes, glucose-lowering per se is likely to reduce cardiovascular events [32]. For example, reduction in cardiovascular events has been demonstrated with a metformin-based glucose-lowering treatment strategy [39] and in a meta-analysis describing UK Prospective Diabetes Study data combined with three large trials [30]. Published prospective cardiovascular outcome studies of pharmaceutical agents have been conducted under the guiding principle of glycemic equipoise to better evaluate the safety of the pharmaceutical agent under study, although glycemic equipoise does not apply to all ongoing cardiovascular outcome studies [40, 41]. The glycemic-equipoise design has the potential to bring out pleiotropic actions of a drug, in addition to glucose lowering, although treatment differences in HbA1c can still occur. The EMPA-REG outcome trial in 7020 patients with type 2 diabetes, which evaluated the oral sodium-glucose cotransporter 2 inhibitor empagliflozin, is the only study thus far showing a risk reduction (of $14 \%$ ) in MACE (risk ratio of 0.86
[95 \% CI, 0.74 to 0.99]), while an additional benefit was observed in hospitalizations for heart failure [28].

Prior to this analysis, pramlintide as a pharmaceutical agent was considered neutral with regard to risk of cardiovascular events, and that view has not changed based on the current findings. The efficacy of pramlintide in improving post-meal hyperglycemia and long-term glycemic control $(-0.6 \%$ HbA1c reduction vs. placebo $[12,13])$ in inadequately controlled diabetes in combination with insulin, without weight gain (or with weight loss), can plausibly help reduce the hyperglycemiamediated cardiovascular risk, but that has not been formally tested. The mechanism of action of pramlintide includes delayed gastric emptying, modulation of satiety leading to decreased food intake, and reduction of post-meal glucagon secretion, resulting in more efficient insulin action with regard to glucose disposal following ingestion of exogenous glucose (reviewed in Hinshaw et al. [4]). Furthermore, pramlintide has been associated with beneficial effects on body weight, lipids (total cholesterol, low-density lipoprotein cholesterol, and triglycerides) [42], as well as other emerging cardiovascular risk markers [42-45]. Combined, these features of pramlintide are consistent with the absence of an excess risk of cardiovascular events associated with its use.

\section{Conclusions}

The findings of the current retrospective pooled analysis add to the body of safety data on pramlintide use in patients with type 2 diabetes inadequately controlled on insulin. The findings have inherent limitations mostly attributed to the short observation period (16 to 52 weeks) and relatively small sample size, but these are less likely to have influenced the results because the cardiovascular event rate in the pooled assessment was sufficient for robust statistical analyses. The cardiovascular events analyzed were investigator-reported MACE that had occurred in the clinical trials, and had been categorized according to standardized regulatory medical definitions. In conclusion, this new analysis of pooled clinical trial data showed that there was no increased risk of MACE associated with pramlintide therapy versus comparator treatment in patients with type 2 diabetes using insulin.

\section{Abbreviations}

AEs: Adverse events; BID: Twice daily; Cl: Confidence interval; CV: Cardiovascular; HbA1c: Glycated hemoglobin; HR: Hazard ratio; MACE: Major adverse cardiovascular events; MedDRA: Medical Dictionary for Regulatory Activities; RR: Relative risk; SFU: Sulfonylurea; SMQ

MACE: Standardized MedDRA query for MACE; TID: Three times daily; TZD: Thiazolidinedione.

Competing interests

$\mathrm{KH}$ was an employee of AstraZeneca at the time of the preparation of the manuscript. MZ and AW are employees of Bristol-Myers Squibb. TWAdB is an employee of AstraZeneca. 


\section{Authors' contributions}

$\mathrm{KH}, \mathrm{MZ}$, and $\mathrm{AW}$ contributed to the study design. $\mathrm{MZ}$ analyzed the data. $\mathrm{KH}$, AW, and TWAdB contributed to the interpretation of the results. All authors critically reviewed and edited the manuscript, and approved the final version.

\section{Acknowledgements}

Medical writing support was provided by Meredith Rogers, MS, formerly of Bristol-Myers Squibb, and Sushma Soni of inScience Communications, Springer Healthcare (Philadelphia, PA, USA), which was funded by AstraZeneca.

\section{Funding}

The design and conduct of the analysis were supported by Amylin Pharmaceuticals, a wholly owned subsidiary of AstraZeneca. Medical writing support to assist in preparation of the manuscript was funded by AstraZeneca.

\section{Author details}

'Bristol-Myers Squibb/AstraZeneca, San Diego, CA, USA. Bristol-Myers Squibb, Hopewell, NJ, USA. ${ }^{3}$ AstraZeneca CVMD GMD, One Medimmune Way, Gaithersburg, MD 20878, USA.

\section{Received: 31 December 2015 Accepted: 19 April 2016}

Published online: 11 May 2016

\section{References}

1. Ludvik B, Lell B, Hartter E, Schnack C, Prager R. Decrease of stimulated amylin release precedes impairment of insulin secretion in type II diabetes. Diabetes. 1991;40:1615-9.

2. Koda JE, Fineman M, Rink TJ, Dailey GE, Muchmore DB, Linarelli LG. Amylin concentrations and glucose control. Lancet. 1992;339:1179-80.

3. Chance WT, Balasubramaniam A, Zhang FS, Wimalawansa SJ, Fischer JE. Anorexia following the intrahypothalamic administration of amylin. Brain Res. 1991;539:352-4.

4. Hinshaw L, Schiavon M, Mallad A, Man CD, Basu R, Bharucha AE, et al. Effects of delayed gastric emptying on postprandial glucose kinetics, insulin sensitivity, and beta-cell function. Am J Physiol Endocrinol Metab. 2014;307: E494-502.

5. Riddle MC, Yuen KC, de Bruin TW, Herrmann K, Xu J, Ohman P, et al. Fixed ratio dosing of pramlintide with regular insulin before a standard meal in patients with type 1 diabetes. Diabetes Obes Metab. 2015;17:904-7.

6. Buse JB, DeFronzo RA, Rosenstock J, Kim T, Burns C, Skare S, et al. The primary glucose-lowering effect of metformin resides in the gut, not the circulation: results from short-term pharmacokinetic and 12-week doseranging studies. Diabetes Care. 2016;39:198-205.

7. Fineman MS, Koda JE, Shen LZ, Strobel SA, Maggs DG, Weyer C, et al. The human amylin analog, pramlintide, corrects postprandial hyperglucagonemia in patients with type 1 diabetes. Metabolism. 2002:51:636-41.

8. Weyer C, Maggs DG, Young AA, Kolterman OG. Amylin replacement with pramlintide as an adjunct to insulin therapy in type 1 and type 2 diabetes mellitus: a physiological approach toward improved metabolic control. Curr Pharm Des. 2001;7:1353-73.

9. Edelman S, Garg S, Frias J, Maggs D, Wang Y, Zhang B, et al. A double-blind, placebo-controlled trial assessing pramlintide treatment in the setting of intensive insulin therapy in type 1 diabetes. Diabetes Care. 2006;29:2189-95.

10. Ratner RE, Dickey R, Fineman M, Maggs DG, Shen L, Strobel SA, et al. Amylin replacement with pramlintide as an adjunct to insulin therapy improves long-term glycaemic and weight control in type 1 diabetes mellitus: a 1year, randomized controlled trial. Diabet Med. 2004;21:1204-12.

11. Whitehouse F, Kruger DF, Fineman M, Shen L, Ruggles JA, Maggs DG, et al. A randomized study and open-label extension evaluating the long-term efficacy of pramlintide as an adjunct to insulin therapy in type 1 diabetes. Diabetes Care. 2002;25:724-30.

12. Hollander PA, Levy P, Fineman MS, Maggs DG, Shen LZ, Strobel SA, et al. Pramlintide as an adjunct to insulin therapy improves long-term glycemic and weight control in patients with type 2 diabetes: a 1-year randomized controlled trial. Diabetes Care. 2003;26:784-90.

13. Ratner RE, Want LL, Fineman MS, Velte MJ, Ruggles JA, Gottlieb A, et al. Adjunctive therapy with the amylin analogue pramlintide leads to a combined improvement in glycemic and weight control in insulin-treated subjects with type 2 diabetes. Diabetes Technol Ther. 2002;4:51-61.

14. AstraZeneca Pharmaceuticals LP. Data on file (Clinical Study Report: Protocol 137-123) 2000.
15. Riddle M, Frias J, Zhang B, Maier H, Brown C, Lutz K, et al. Pramlintide improved glycemic control and reduced weight in patients with type 2 diabetes using basal insulin. Diabetes Care. 2007;30:2794-9.

16. Riddle M, Pencek R, Charenkavanich S, Lutz K, Wilhelm K, Porter L. Randomized comparison of pramlintide or mealtime insulin added to basal insulin treatment for patients with type 2 diabetes. Diabetes Care. 2009;32:1577-82.

17. Frederich R, Alexander JH, Fiedorek FT, Donovan M, Berglind N, Harris S, et al. A systematic assessment of cardiovascular outcomes in the saxagliptin drug development program for type 2 diabetes. Postgrad Med. 2010;122:16-27.

18. Iqbal N, Parker A, Frederich R, Donovan M, Hirshberg B. Assessment of the cardiovascular safety of saxagliptin in patients with type 2 diabetes mellitus: pooled analysis of 20 clinical trials. Cardiovasc Diabetol. 2014;13:33.

19. White WB, Pratley R, Fleck P, Munsaka M, Hisada M, Wilson C, et al. Cardiovascular safety of the dipetidyl peptidase-4 inhibitor alogliptin in type 2 diabetes mellitus. Diabetes Obes Metab. 2013;15:668-73.

20. US Food and Drug Administration Center for Drug Evaluation and Research. Guidance for industry. Diabetes mellitus —evaluating cardiovascular risk in new antidiabetic therapies to treat type 2 diabetes. 2008. http://www.fda. gov/downloads/Drugs/GuidanceComplianceRegulatoryInformation/ Guidances/ucm071627.pdf. Accessed November 16, 2015.

21. Mozzicato P. Standardised MedDRA queries: their role in signal detection. Drug Saf. 2007;30:617-9.

22. Ratner R, Han J, Nicewarner D, Yushmanova I, Hoogwerf BJ, Shen L. Cardiovascular safety of exenatide BID: an integrated analysis from controlled clinical trials in participants with type 2 diabetes. Cardiovasc Diabetol. 2011;10:22

23. Tancredi M, Rosengren A, Svensson AM, Kosiborod M, Pivodic A, Gudbjornsdottir S, et al. Excess mortality among persons with type 2 diabetes. N Engl J Med. 2015;373:1720-32.

24. Symlin (pramlintide acetate) injection for subcutaneous use: US prescribing information. Wilmington, DE: AstraZeneca Pharmaceuticals LP. 2015.

25. ORIGIN Trial Investigators, Gerstein HC, Bosch J, Dagenais GR, Diaz R, Jung $\mathrm{H}$, et al. Basal insulin and cardiovascular and other outcomes in dysglycemia. N Engl J Med. 2012;367:319-28.

26. Green JB, Bethel MA, Armstrong PW, Buse JB, Engel SS, Garg J, et al. Effect of sitagliptin on cardiovascular outcomes in type 2 diabetes. N Engl J Med. 2015:373:232-42.

27. Scirica BM, Bhatt DL, Braunwald E, Steg PG, Davidson J, Hirshberg B, et al. Saxagliptin and cardiovascular outcomes in patients with type 2 diabetes mellitus. N Engl J Med. 2013;369:1317-26.

28. Zinman B, Wanner C, Lachin JM, Fitchett D, Bluhmki E, Hantel S, et al. Empagliflozin, cardiovascular outcomes, and mortality in type 2 diabetes. $\mathrm{N}$ Engl J Med. 2015;373:2117-28.

29. Marso SP, Lindsey JB, Stolker JM, House JA, Martinez Ravn G, Kennedy KF, et al. Cardiovascular safety of liraglutide assessed in a patient-level pooled analysis of phase 2: 3 liraglutide clinical development studies. Diab Vasc Dis Res. 2011;8:237-40.

30. Turnbull FM, Abraira C, Anderson RJ, Byington RP, Chalmers JP, Duckworth WC, et al. Intensive glucose control and macrovascular outcomes in type 2 diabetes. Diabetologia. 2009;52:2288-98.

31. Seaquist ER, Anderson J, Childs B, Cryer P, Dagogo-Jack S, Fish L, et al. Hypoglycemia and diabetes: a report of a workgroup of the American Diabetes Association and the Endocrine Society. Diabetes Care. 2013;36: 1384-95.

32. Holman RR, Sourij H, Califf RM. Cardiovascular outcome trials of glucoselowering drugs or strategies in type 2 diabetes. Lancet. 2014;383:2008-17.

33. Snell-Bergeon JK, Wadwa RP. Hypoglycemia, diabetes, and cardiovascular disease. Diabetes Technol Ther. 2012;14 Suppl 1:S51-8.

34. Desouza C, Salazar H, Cheong B, Murgo J, Fonseca V. Association of hypoglycemia and cardiac ischemia: a study based on continuous monitoring. Diabetes Care. 2003;26:1485-9.

35. Duh E, Feinglos M. Hypoglycemia-induced angina pectoris in a patient with diabetes mellitus. Ann Intern Med. 1994;121:945-6.

36. Action to Control Cardiovascular Risk in Diabetes Study Group, Gerstein HC, Miller ME, Byington RP, Goff Jr DC, Bigger JT, et al. Effects of intensive glucose lowering in type 2 diabetes. N Engl J Med. 2008;358:2545-59.

37. Bonds $\mathrm{DE}$, Miller ME, Bergenstal RM, Buse JB, Byington RP, Cutler JA, et al. The association between symptomatic, severe hypoglycaemia and mortality in type 2 diabetes: retrospective epidemiological analysis of the ACCORD study. BMJ. 2010;340:b4909. 
38. Zoungas S, Patel A, Chalmers J, de Galan BE, Li Q, Billot L, et al. Severe hypoglycemia and risks of vascular events and death. N Engl J Med. 2010; 363:1410-8.

39. Holman RR, Paul SK, Bethel MA, Matthews DR, Neil HA. 10-year follow-up of intensive glucose control in type 2 diabetes. N Engl J Med. 2008;359:1577-89.

40. Marso SP, Poulter NR, Nissen SE, Nauck MA, Zinman B, Daniels GH, et al. Design of the liraglutide effect and action in diabetes: evaluation of cardiovascular outcome results (LEADER) trial. Am Heart J. 2013;166:823-30.

41. Holman RR, Bethel MA, George J, Sourij H, Doran Z, Keenan J, et al. Rationale and design of the EXenatide Study of Cardiovascular Event Lowering (EXSCEL) trial. Am Heart J. 2016;174:103-10.

42. Azimova K, San Juan Z, Mukherjee D. Cardiovascular safety profile of currently available diabetic drugs. Ochsner J. 2014;14:616-32.

43. Hoogwerf BJ, Doshi KB, Diab D. Pramlintide, the synthetic analogue of amylin: physiology, pathophysiology, and effects on glycemic control, body weight, and selected biomarkers of vascular risk. Vasc Health Risk Manag. 2008:4:355-62.

44. Wysham C, Lush C, Zhang B, Maier H, Wilhelm K. Effect of pramlintide as an adjunct to basal insulin on markers of cardiovascular risk in patients with type 2 diabetes. Curr Med Res Opin. 2008;24:79-85.

45. Levetan C, Want LL, Weyer C, Strobel SA, Crean J, Wang Y, et al. Impact of pramlintide on glucose fluctuations and postprandial glucose, glucagon, and triglyceride excursions among patients with type 1 diabetes intensively treated with insulin pumps. Diabetes Care. 2003;26:1-8.

Submit your next manuscript to BioMed Central and we will help you at every step:

- We accept pre-submission inquiries

- Our selector tool helps you to find the most relevant journal

- We provide round the clock customer support

- Convenient online submission

- Thorough peer review

- Inclusion in PubMed and all major indexing services

- Maximum visibility for your research

Submit your manuscript at www.biomedcentral.com/submit
Biomed Central 